\title{
Lecture Capture: An Effective Tool for Uni- versal Instructional Design?
}

Susan Watt, Susan Vajoczki, \& Geraldine Voros

McMaster University

Michelle Vine and Nancy Fenton

University of Waterloo

Jacob Tarkowski

York University

\begin{abstract}
Student enrolment and instructional accommodation requests are rising in higher education. Universities lack the capacity to meet increasing accommodation needs, thus research in this area is required. In Ontario, new provincial legislation requires that all public institutions, including universities, make their services accessible to persons with disabilities. The objective of the Accessibility for Ontarians with Disabilities Act (AODA) is to provide universal access for students with disabilities. The purpose of this case study is to understand the experiences of students regarding the ability of a lecture capture technology to align with the principles of Universal Instructional Design (UID). Data were collected using a mixed-method research design: (a) an online questionnaire, and (b) individual face-to-face interviews. Scholarship of Teaching and Learning (SoTL) literature provides a useful background to explore AODA legislation and universal accessibility vis-à-vis lecture capture technologies. Results indicate that lecture capture can align both with the principles of UID and AODA.
\end{abstract}

\section{Résumé}

Il existe une recrudescence des inscriptions étudiantes et des demandes d'adaptations éducatives en enseignement supérieur. Les universités n'ayant pas la capacité de répondre aux besoins d'adaptations croissants, il y a un 
besoin de recherche dans ce domaine. La nouvelle législation provinciale de l'Ontario, au Canada, exige que toutes les institutions publiques, y compris les universités, rendent leurs services accessibles aux personnes handicapées. L'objectif de la Loi sur l'accessibilité pour les personnes handicapées de l'Ontario (LAPHO) est de fournir un accès universel aux étudiants en situation de handicap. La présente étude de cas vise à comprendre, à partir des expériences des étudiants, la capacité de la technologie d'enregistrement de cours magistraux à s'aligner avec les principes de Conception universelle de l'apprentissage (CUA). Les données ont été colligées par des méthodes de recherche mixtes : 1) un questionnaire en ligne; et 2) des entretiens individuels. La littérature sur l'avancement des connaissances en enseignement et en apprentissage (ACEA) fournit le contexte de cette étude et permet d'explorer la LAPHO et l'accessibilité universelle en regard des technologies d'enregistrement de cours magistraux. Les résultats indiquent que l'enregistrement de cours magistraux peut être conforme aux principes de la CUA et de la LAPHO.

As higher education enrolment continues to rise in North America, so do the associated challenges (e.g., demands on the existing physical and human resources of universities). The Association of Universities and Colleges of Canada (AUCC, 2007) indicated that Canadian university enrolment is anticipated to increase by 70,000 to 150,000 fulltime students over the next decade. McMaster University's undergraduate enrolment has increased by more than 50\% since 2000-2001 (Busch-Vishniac, 2007). There has also been synonymous growth in the prevalence of students with identified disabilities. The number of university students with psychological, physical, and learning disabilities has tripled in the US since the 1970 (Pliner \& Johnson, 2004). Similarly, the number of students with disabilities registered in Ontario universities has tripled between 1991-1992 and 2007-2008 (Council of Ontario Universities [COU], 2010). Accompanying these increases are more requests for accommodation, as well as a classification of needs beyond the classroom.

It is thought that a large number of unreported accommodation needs exist in addition to those formally reported by students. This includes a multitude of student needs beyond the classroom that are often overlooked (e.g., childcare, transportation, family care, and employment). Growth in both the number of formal accommodation requests and the breadth and number of unreported accommodation needs have created a new challenge for universities. Instructors have expressed concern about their ability to meet this range of needs. In many cases, increasing enrolment has already led to larger undergraduate classes than in the past and has put strain on resources. As a result, researchers have begun to investigate how lecture capture technology can address the diverse needs of the current student population while aligning with recent legislation.

Our primary research objective was to understand the perceptions and experiences of students, particularly those with disabilities, with regard to lecture capture technology to evaluate how well the technology aligns with the principles of Universal Instructional Design (UID). Although the sample included a very small number of students with disabilities, we resolved this shortcoming by expanding our focus to examine all students' 
experiences. Specifically, this case study investigates the ability of lecture capture technology to act as a supplementary delivery mechanism of course material to students. It explores all students' perceptions and experiences with a particular lecture capture technology (echo360), including how these lectures can be mapped to the principles of UID. Finally, the implications of universally accessible course materials will be considered in the context of classroom barriers and accommodation needs of students with disabilities.

In Ontario, new legislation requires that public sector institutions, including universities, make all of their services accessible to all persons with disabilities. The Accessibility for Ontarians with Disabilities Act (AODA) draws attention to the use of lecture capture technologies as a mechanism for meeting the needs of students with disabilities. The objective of the AODA legislation is to break down barriers by mandating universal accessibility. This proactive legislation requires that barriers be removed by the year 2025 through an incremental integration process. Failure to comply could lead to legal challenges against universities, including complaints under the Human Rights' Code (Ontario Human Rights Code [OHRC], 1990).

AODA represents a more comprehensive legislative and regulatory framework than its predecessor, the Ontarians with Disabilities Act (Beer, 2010). The new AODA legislation represents a shift in values and attitudes about equitable access to many services, including higher education. A commitment to equity, within this context, requires the recognition of students' varying background knowledge, readiness, language, and preferences in learning and interests (Hall et al., 2009). This legislation places responsibility on the public, private and not-for-profit sectors to develop, implement, and enforce a set of mandatory accessibility standards. It also requires the participation of persons with disabilities and other stakeholders from involved organizations in the development of the accessibility standards (Beer, 2010). These changes are intended to foster a transition from an environment in which students are required to report their disabilities to secure necessary accommodations, to one in which environments incorporate universal accessibility into mainstream delivery mechanisms. AODA builds upon five key principles: accessible customer service, accessible information and communications, accessible physical environments, employment accessibility, and accessible transportation (Ministry of Community and Social Services [MCSS], 2008). In the context of a university, universal accessibility with respect to information and communications calls for implementation of UID principles. Such changes will lessen the need to report disabilities and to seek individual accommodations.

\section{Principles of Universal Design and Universal Instructional Design}

Universal Design (UD) practices are predicated on the principle of inclusion with a goal to achieve access, equity, and excellence for students (Mino, 2004; Scott, McGuire \& Foley, 2003). Lecture capture technologies are one method of achieving UD through the provision of broader access to instruction by increasing flexibility of and enabling more students control over learning experiences (Brogan, 2009). These technologies support the concepts of UD by making lectures available in multiple formats through online recordings, enabling students to review lectures outside the classroom (Williams \& Fardon, 2005).

UD emphasizes "the design of products and environments that are usable by all people, to the greatest extent possible, without the need for adaptation or specialized design" 
(Burgstahler, 2005, p.1). The origin of UD is rooted in the field of architecture, where architects learned how to embed accessibility features into their original designs, which resulted in a broad range of appreciation for the new accessibility features (Ianiro, 2007). These principles can be applied to teaching in order to address the barriers that students experience in accessing curricula and instruction (Pliner \& Johnson, 2004). Baycrest (2010) identifies seven such education-related barriers: (1) attitudinal, (2) architectural, (3) informational/communicational, (4) physical, (5) policy and practices, (6) technology, and, (7) other. As a result, the term Universal Instructional Design has been coined for the application of universal design to education. Accordingly, UID ${ }^{1}$ represents "a new paradigm for teaching, learning, and assessment, drawing on new brain research and new media technologies to respond to individual learner differences" (Pliner \& Johnson, 2004, p.107).

UID is a process that considers the potential needs of all learners by identifying and eliminating unnecessary barriers to teaching and learning when designing and delivering instruction, while maintaining academic rigor (Pliner \& Johnson, 2004). An implicit assumption within UID is that, in addressing the needs of students with disabilities, there is an element of equity and inclusiveness that is passed on to others as well. Pliner \& Johnson (2004) find that all students can benefit from improved access to instructional materials.

Edyburn (2005) proposes three steps in the transition from a system that requires a student to request accommodation to one of universal accessibility: (1) advocacy, (2) accommodation, and (3) accessibility. Advocacy raises awareness of inequity and provides a stimulus to induce change. Accommodation involves the modification of environments to accommodate requests. Finally, accessibility involves attaining "an environment where access is equitably provided to everyone at the same time" (Edyburn, 2005, p.19).

UID involves the identification and removal of unnecessary barriers to learning. It originates from a set of nine primary principles: (1) equitable use, (2) flexibility in use, (3) simple and intuitive, (4) perceptible information, (5) tolerance for error, (6) low physical effort, (7) size and space for approach and use, (8) a community of learners, and (9) instructional climate (Scott et al., 2003). Achieving accessibility and equity and conforming to AODA standards within the classroom requires consideration of these principles. With increasing diversity in the classroom, instruction that is cognizant of these principles assumes the burden of adaptation-rather than requiring students to adapt- to minimize barriers and maximize access to information and learning (Hall et al., 2009).

\section{Lecture Capture Technologies}

The process of recording lectures is an established mechanism for providing alternative access for students, including students with disabilities. Research has shown that providing access to lectures (i.e., recording audio and video materials together) outside the classroom benefits most students (Brogan, 2009; Williams, 2006). Students cite convenience, flexibility, and positive impact on learning as key reasons that recorded lectures are beneficial (Fernandez, Simo, \& Sallan, 2009; Vajoczki, Watt, \& Marquis, 2008; Vajoczki, Watt, Marquis, \& Holshausen, 2010; Vajoczki, Watt, Marquis, Liao, \& Vine, 2011). These technologies benefit students with learning disabilities, enabling them more control over their learning experiences and greater accessibility to lectures online with respect to both auditory and visual content (Williams \& Fardon, 2005). Lecture capture 
systems make recordings accessible online in order to enable students to review lectures outside of the classroom setting (Williams \& Fardon, 2005).

UID affords students with a broad range of disabilities a more equal opportunity to participate in higher education (Fuller, Healey, Bradley, \& Hall, 2004), providing them with independence over their learning environments. Research has shown that learning is enhanced in contexts where learners have control over their learning processes (Mino, 2004). To facilitate accessibility, high-resolution digital cameras capture the contents of a whiteboard or overhead projector to develop presentations for students (with or without) a disability, without requiring the lecturer to adopt new technologies (Hughes \& Robinson, 2008). Most importantly, designing a process to facilitate access for individuals with disabilities carries with it the possibility of improved usability for all students (Hall et al., 2009).

Lectopia is a lecture capture system that provides automated recording of audio and video material from lectures for delivery to students via the internet (Williams, 2006). The goal of this system is to capture the lecture without obstructing the lecturing process in order to minimize disruption for the lecturer. Williams (2006) demonstrated that the system was effective in addressing the needs of students with disabilities. A survey of students with acknowledged disabilities or medical conditions on their enrolment forms indicated that $65 \%$ saw Lectopia as an essential learning resource, with $60 \%$ reporting it should be made compulsory across campus (Williams, 2006).

A study by Hughes \& Robinson (2008), who examined a system called Photonote, showed that individuals who habitually used a university-appointed note-taker were more likely to benefit from the use of this system than from their personal or note-taker materials (Hughes \& Robinson, 2008).

Following a pilot-test and extensive product review by McMaster University, echo360 was the chosen delivery mechanism as a first step in complying with the new AODA regulations. It is a commercial lecture capture system that allows for the automation of scheduling, capturing, packaging, publishing, and distribution of recorded content, facilitating easy access to information (Brogan, 2009). This system generates media in a variety of forms, including: audio podcasts, enhanced podcasts, vodcasts, and full rich media playback environments. This form of lecture capture appears to be in line with the principles of UID, as it applies to educational settings, and places particular emphasis on technology as a tool for accessing the curriculum (Scott et al., 2003). Pliner \& Johnson (2004) argue that lecture capture creates "barrier-free environments that are naturally inclusive that require minimal amounts of adaptation [that] would alleviate much of the tension that results when disability interacts with institutions, systems, space and culture" (p. 107). In doing so, Pliner \& Johnson (2004) suggest that lecture capture supports "an awareness of the unique nature of each learner and the need to accommodate differences, creating learning experiences that suit the learner and maximize his or her ability to progress" (p.107), all of which align with the principles of UID.

\section{The Research Site: McMaster University}

McMaster University, as a public sector institution, falls within the Accessibility Directorate of Ontario's mandate to maintain its public education function. Resource infrastructure has been built within AODA to ensure that all levels of the education system are consulted in order to build accessibility into the educational experience (Beer, 2010) and 
to ensure actions are in compliance with the legislated requirements. More specifically, McMaster's role as a public education institution places emphasis on the accessible information and communications requirement of the AODA mandate-one of the first parts to be implemented. This requirement states that standards should be in place to "address the removal of barriers in access to information. These standards may include information being provided in person, through print, a website or other means" (MCSS, 2008).

At McMaster University, almost 6\% (1220 students) of undergraduate students formally reported an accommodation need in 2010 (Centre for Student Development [CSD], 2010). This is likely an underestimate of the total population of students with disabilities given there is no obligation for students to report a disability. Mental health was the most commonly declared disability (37\%), followed by learning disabilities/attention deficit disorder and screening (16\%), and students with chronic illness (11\%). This is consistent with Ontario universities in general, as the number of self-identified university students with psychiatric disabilities increased 128\% between 2003-2004 and 2007-2008 (COU, 2010). What is not taken into consideration, however, is the notion of diversifying student needs for accommodation outside of the classroom, including childcare, transportation, family care, and employment.

In 2007, investigators in the Faculty of Social Sciences at McMaster University, in which more than $20 \%$ of the undergraduate student population was enrolled, began a research project designed to examine the efficacy of podcasts/vodcasts as teaching and learning tools (Vajoczki et al., 2008, 2010, 2011). Results from this research demonstrated a range of positive outcomes of pod/vodcasting: (1) easy to use review and study resource (2) helpful tool to accommodate learning needs of some students with disabilities, (3) higher grades earned by students who made use of the pod/vodcasts, and (4) assistance to faculty in providing enhanced learning experiences. In particular, more than $81 \%$ of students who identified a need for accommodation reported podcasts to be helpful. The general feedback found lecture capturing successfully met a number of student accommodation needs.

In 2008, three echo360 lecture capture applications were purchased and installed in some of McMaster's most heavily used, high capacity classrooms. In the 2009-2010 academic year, they were used to produce lecture captures for large enrolment classes in three main Faculties (i.e., Engineering, Sciences, and Social Sciences) across the University, demonstrating movement from a single isolated research activity to a universitywide policy initiative. Additional systems were purchased through 2011-2012.

While lecture capture technologies offer students access to instructional materials, the potential benefits are accompanied by financial, technical, and pedagogical challenges. The use of lecture capture technology also raises issues of privacy and copyright infringement (Flanagan \& Calandra, 2005). Faculty who choose to use these technologies must take necessary precautions to protect their intellectual property and obtain copyright clearance for materials used. The use of lecture capturing also shifts student expectations and practices from information transfer to a more student-centred and interactive format. As a result, instructors may need to devote more time in class to enable students to practice skills and apply what they have heard in lecture (McKenzie, 2008). 


\section{The Research Study}

This case study is concerned with evaluating lecture capture, specifically the platform echo36o, as a learning tool for students. It is not meant to be an assessment of student learning per se, instead focusing on questions about how students access information. Although the original intent was to examine the experience of students with disabilities, this has proven to be a methodological limitation. Very few students with disabilities (either reported or unreported accommodation needs) were captured in the survey sample; thus, the researchers expanded the scope of the case study to examine the experience of all students. This limitation highlighted a new question within this type of research: What is the most effective way to capture the perspective of students with disabilities in their learning environment considering that they typically represent a small proportion of the overall class? Our assessment focuses on how all students perceived and experienced lecture capture. Findings are supplemented with survey data from a small sample $(n=15)$ of students with reported and unreported accommodation needs. We recognize that these data are not sufficient to generalize about the experience of students with disabilities, however, they do provide a sample to allow us to raise questions for future research.

We undertook a case study in a Level II course in the Faculty of Social Sciences at McMaster University, entitled Canadian Children, which is offered as an evening course in a three-hour block. Because the course has no prerequisite, students enroll from all levels and all Faculties. The students are provided access to lecture captures in two stages through the learning management system (LMS). The audio and visual portion of the lecture are posted approximately 24 hours after the lecture, and then two to three days later the closed captioning (i.e., text) is also posted. The instructor of the course is a teaching stream faculty member who has used lecture capture in multiple courses. The instructor was particularly interested in pilot testing closed captioning and assessing its influence on accessibility of the learning materials. Students in this course are provided the following learning tools in addition to the captured lectures: three textbooks, overhead slides posted on the LMS, and three office hours per week with the instructor, with the option to make an appointment outside scheduled office hours. Assessment is conducted twice throughout the term and consists of a mid-term examination (50\%) and a final examination (50\%).

A two-stage, mixed methods research design included an online questionnaire and individual face-to-face interviews. Research participants ( $\mathrm{n}=175 ; 32 \%$ response rate) were recruited from the Canadian Children course $(\mathrm{N}=542)$. In stage one, survey questions asked students about the utility of lecture capturing, academic accommodations or needs, and perceptions/experiences of lecture capturing. Stage two involved individual face-toface interviews with students $(n=8)$ and a faculty member $(n=1)$ selected from phase one. Key themes from stage one informed the development of the qualitative interview guide used to deepen our understanding of the perspectives and experiences of students who utilize lecture capture technologies. Students were also probed to expand upon the technical aspects of lecture capture, the need for systems and supports, and what measures were necessary to make courses more accessible.

Survey data were cleaned, coded, and analyzed using the Statistical Package for the Social Sciences (SPSS). Thematic content analysis of the interviews was undertaken using qualitative data analysis software (QSR, NVivo 9.0). This research received clearance from the McMaster University Research Ethics Board. 


\section{Results}

\section{Stage I: Online Questionnaire}

All students in the course were sent an email invitation to participate in the online questionnaire in mid-March of the winter term. The questionnaire contained 40 multiple choice and Likert Scale questions and took between 15 and 20 minutes to complete. A copy of the online questionnaire is available in Appendix 1.

Results illustrate that $40 \%$ of respondents said the availability of lecture capture influenced their choice to register in the course. Ninety-three percent of all respondents used at least one feature of lecture capture during the course term. Fifty-four percent of students who used lecture capturing also used the closed captioning feature; and, more than $80 \%$ of students who used the closed captioning used it more than $50 \%$ of the time. Approximately $70 \%$ of respondents (68\%) used lecture capture for $\geq 50 \%$ of lectures in course; $34 \%$ viewed all lectures; $83.5 \%$ estimated that they viewed $\geq 50 \%$ of any individual lecture; and, $44 \%$ indicated that they used all of the content of captured lectures.

Students endorsed using lecture capturing for a variety of reasons: $69 \%$ of students cited the ability to work at their own pace, $60 \%$ cited its availability, $41 \%$ revealed that it "allowed [them] to miss a lecture," and $43 \%$ indicated that it gave them a better understanding of course material.

Respondents reported a variety of ways in which they made use of lecture capturing. For example, $61 \%$ of students cited studying for tests as its most common application. Fifty-five percent of students identified catching up on a missed materials as its most common application, while $21 \%$ of students used lecture capturing in lieu of attending class. Almost half of the students (42\%) used lecture capture after class for review and clarification.

Students indicated a variety of methods and locations in which they accessed the lecture captures. Eighty-two percent of students used laptop computers, 22\% used desktop computers, $5 \%$ used mp3 players, $1 \%$ used cell phones, and $<1 \%$ used game consoles. With respect to location, $85 \%$ of respondents accessed the lectures from home, $30 \%$ accessed them at school on their wireless laptop, $23 \%$ accessed them at home while completing other tasks, and $5 \%$ accessed the lecture captures while commuting.

Nine percent of respondents $(n=15)$ identified that they had one or more academic accommodation need(s). Six percent of respondents had a reported academic accommodation need, of which $80 \%$ found lecture capturing helpful in meeting those needs. An additional $3 \%$ of respondents cited unreported accommodation needs, $60 \%$ of whom found lecture capturing helpful in meeting those needs.

Respondents were asked to evaluate their experience of using the lecture captures. Almost 79\% indicated that lecture capture helped improve their overall understanding of course material. An equal proportion of respondents (79\%) thought that lecture capture helped them to retain the knowledge that they learned in the course.

\section{Stage II: Qualitative Interviews}

All students who completed the online questionnaire were asked whether they were interested in participating in a follow-up interview. Eight students indicated that they wished to participate and were interviewed by a research assistant. The interviews were 
conducted to further explore findings from the quantitative data. Sample interview guides for both students $(n=8)$ and the instructor $(n=1)$ can be found in Appendix 2.

Student interviews $(n=8)$ were analyzed by mapping interview data to the nine principles of UID (Scott et al., 2003). Sections of coded text were identified and paired with each of the different principles, as seen in Table 1. For example, Pliner \& Johnson (2004) define equitable use as "making classroom material accessible to diverse learning needs and styles" (p. 107). Statements that were consistent with the definition of equitable use included: “...I can concentrate better during nights, so I usually do that" and “...[if] you needed to have a reference for something that was said...or a topic that was said, I mean it [lecture capture] was totally accessible." Seventy-five percent of student respondents identified equitable use, $38 \%$ identified flexibility in use, $38 \%$ identified simple and intuitive course content, $38 \%$ identified perceptible information, $63 \%$ identified tolerance for error, 38\% identified low physical effort, $13 \%$ identified size and space for approach and use, $38 \%$ indicated that lecture capture helped to facilitate a community for learning, and 63\% identified instructional climate (see Table 1).

In an attempt to substantiate both the survey and interview data, several survey questions about UID from the phase one questionnaire were matched with the principles of UID (final column of Table 1). This was a pilot methodology that only captured four of the nine principles of UID. It was undertaken by incorporating the definition of each principle within a statement that offered a Likert Scale response, with five options ranging from Strongly Agree to Strongly Disagree. For example, using the same example of equitable use, the statement read: "Lecture capturing allows all students, regardless of learning abilities, an equitable learning experience." The intent is to incorporate statements mapped to all nine principles in future phases of this research project. There were a higher number of responses to these statements $(n \approx 149)$ than there were for the qualitative UID interview mapping. Equitable use was endorsed by $91 \%$ of student respondents, flexibility in use was acknowledged by $89 \%$ of respondents, perceptible information was identified by $65 \%$, and instructional climate was indicated by $85 \%$ of respondents.

Table 1.

Principles of Universal Instructional Design

\begin{tabular}{lcc}
\hline Principle & $\begin{array}{c}\text { Interview } \\
(\%)\end{array}$ & Data \\
\hline Equitable Use & 75 & 91 \\
Flexibility in Use & 38 & 89 \\
Simple and Intuitive & 38 & - \\
Perceptible Information & 38 & 65 \\
Tolerance for Error & 63 & - \\
Low Physical Effort & 38 & - \\
Size and Space for Approach and Use & 13 & - \\
A Community of Learners & 38 & - \\
Instructional Climate & 63 & 85 \\
\hline
\end{tabular}


In order to provide some context for the UID mapping, it is important to understand respondents' perspectives in more detail. With respect to equitable use of lecture capturing, one student said, "I can't write that fast. I have to think of what I am writing, so this just enormously helped me so much..." Another student commented, "I am a mature student with, you know my memory is...not as sharp as it was at seventeen years old...for me to be able to go back and have accessibility to hearing the lecture again, again, and again was absolutely brilliant."

Citing flexibility in use, size, and space for approach and use, as well as low physical effort, one student indicated, "I was really sick this year...without recordings, without something posted online, I would not have even gotten this course, so I 100\% relied on those [lecture captures] in order to continue the course." Not only does lecture capturing address reported disabilities, it can also lead to greater classroom accessibility for mature students, students who are ill, and students who have difficulty keeping up with classroom note-taking. Data also indicate that lecture capturing may address multiple principles of UID from a single student's perspective.

In addition to considering the principles of UID, respondents were asked to identify which, if any, of the seven learning barriers outlined by Baycrest (2010) they encountered, and whether they felt that lecture capturing helped them to overcome these barriers (see Table 2). The number of respondents in this section varied greatly due to misreporting. Misreporting occurred when students claimed that a barrier was alleviated, but had not initially indicated that they encountered the barrier. These respondents were removed from the sample. Thus, responses ranged from $n=3$ (physical barriers) to $n=48$ (other barriers). Thirty-eight percent of respondents indicated that attitudinal barriers were alleviated, $63 \%$ noted an improvement in architectural barriers, $62 \%$ identified improvement in informational/communicational barriers, $67 \%$ indicated that it helped in overcoming physical barriers, $40 \%$ noted improvements in policy and practice barriers, $63 \%$ found help with technology barriers, and 77\% noted improvement in relation to other barriers.

Table 2.

Barriers to Learning

\begin{tabular}{lcc}
\hline Barrier* & $\begin{array}{c}\text { Students } \\
\text { Reporting Barrier } \\
(\#)\end{array}$ & $\begin{array}{c}\text { Alleviated by } \\
\text { Lecture Capture } \\
(\%)\end{array}$ \\
\hline Attitudinal & 8 & 38 \\
Architectural & 8 & 63 \\
Informational/Communicational & 21 & 62 \\
Physical & 3 & 67 \\
Policy \& Practices & 5 & 40 \\
Technology & 19 & 63 \\
Other & 48 & 77 \\
\hline
\end{tabular}

*Definitions can be found in the questionnaire in Appendix I 
The course instructor was asked a set of open-ended questions similar to those asked of student respondents (see Appendix 2). Responses were coded according to the nine principles of UID (Scott et al., 2003). Without being explicitly asked about the principles of UID, the instructor addressed all nine principles. Furthermore, when the instructor was asked whether lecture capturing falls within the definition of UID as a whole, the response was as follows: "[UID] talks more about the flexibility and how to accommodate as many students as you possibly can... so I think that [with] the [lecture capturing], you know we really do meet some of those expectations to a greater degree." Equitable use of lecture capturing was acknowledged: "Having the echo36o, or lecture capturing as well, everybody has the same access, can repeat it as many times as they want, use it as a learning tool, and then that is all normalized..." This point was further supported: "she was laid up in bed at home after a short stay at the hospital, and so now if you don't have [lecture capturing], how do you keep a student like that up to date? Traditionally they would withdraw." The instructor's comments support the usefulness and effectiveness of lecture capturing, specifically with respect to universal accessibility.

\section{Data Limitations}

Although survey respondents were demographically representative of the larger course (i.e. gender, student's faculty affiliation, and level), the modest survey response rate (32\%) is a study limitation. However, this is consistent with literature investigating online survey response rates. Nulty (2008) found that most online surveys obtain a significantly lower response rate (33\%) than paper-based ones (56\%). In addition, Sax et al. (2003) reported even lower response rates in their investigation of web-only surveys: $17.1 \%$ with response incentives, and 19.8\% without response incentives. Although neither investigation determines representation of its samples, both conclude that when characteristics are representative of non-respondents, low response rates do not produce biasing results.

A second limitation is that students with accommodation needs represent a small proportion of the entire student body; therefore, the number of students who identified either reported or unreported accommodation needs in this study was also small. As a result of this limitation, the authors are not suggesting the data is generalizable, but rather that it does hold validity within this case study. It is important to reiterate that although the original intent was to examine the experiences of students with disabilities, this proved to be a methodological limitation. This not only resulted in an expansion of the scope of the study to examine the experiences of all students, but also posed additional questions around the most effective way to capture the perspectives of students with disabilities.

It is also important to note the differences in the data presented in Table 1: a) responses to qualitative interview questions were coded thematically according to the nine principles of UID proposed by Scott et al. (2003), whereas, the quantitative data consisted of dichotomous responses to survey questions; and, b) there was a much smaller sample in phase two $(\mathrm{n}=8)$ than in phase one $(\mathrm{n} \approx 149)$, so it would be difficult, and perhaps inappropriate, to make direct comparisons between the qualitative and quantitative data in Table 1. Rather, in using more than one data collection technique, or by employing methodological triangulation, "the underlying assumption is that the validity of research results is enhanced if the different methodological approaches produce convergent findings about the same empirical domain” (Erzerberger \& Prein, 1997, p.144). 


\section{Discussion}

As previously discussed, UID considers the potential needs of all learners by identifying and eliminating barriers to teaching and learning without forgoing academic rigor or control. It maintains that an element of equity and inclusiveness is passed onto all students, even if the changes are inspired by the needs of those with disabilities. Determining whether lecture capturing is an effective tool for UID required an evaluation of its applicability to the nine principles. Subsequent investigation was necessary to understand students' perceptions and experiences of lecture capturing. This evaluation has developed as a basis for understanding how students with and without disabilities experience lecture capturing. Their encounters with barriers and possible alleviations have also become important in aligning lecture capturing with UID. Finally, a broad evaluation of students' experiences has revealed that equity and inclusiveness can be passed on equally to all students.

Results indicate that lecture capturing aligns itself with the nine principles of UID. Quantitative results indicate that questions paired with four of the principles were met with an endorsement percentage of at least $65 \%$. Furthermore, mapping of the qualitative data from interviews with students revealed that all of the principles were identified in open-ended questions. Statements from both students and instructors during the interviews indicate that, from their perspectives, lecture capturing contributed to meeting the criteria of UID.

All students who responded to the survey used lecture capturing in a variety of ways and were satisfied with the ease of use and quality of captures. Specifically, lecture capturing was cited as being helpful for $80 \%$ of students with reported accommodations and for $60 \%$ of students with unreported accommodation needs. However, an investigation targeting a greater number of students with accommodation needs is required to make any substantial statements. In addition to reinforcing learning, it appears that lecture capturing helped students to deal with the conflicting demands of home, job, and health circumstances while maintaining their studies. Student responses revealed that lecture capturing also helped facilitate barrier removal. These findings suggest that lecture capturing can be used to reduce barriers found in a typical university classroom.

It is important to address the fact that of the students who used lecture capturing, $41 \%$ cited using it because it "allowed [them] to miss a lecture" and $21 \%$ used it "in lieu of attending class." An argument is often made against students' use of lecture capturing in lieu of attending class; however, it is important to understand that learning occurs outside of the classroom as well. Furthermore, this case study is concerned with accommodating diverse student needs and not encouraging attendance.

The results indicate the consistent alignment of lecture capturing with the principles of UID. They subsequently address both reported and unreported accommodations, as well as all of the cited learning barriers. Although findings are based on fair response rates, they do indicate a shift in the direction of AODA recommendations to focus on greater accessibility for all students. When asked if "lecture capturing provides all students, regardless of learning abilities, an equitable learning experience," $89 \%$ of students agreed. Furthermore, $78 \%$ of students felt that lecture capturing both improved their overall understanding of course material and helped them retain the knowledge that they learned in the course. These results indicate that addressing the needs of students with disabilities may carry with it the benefit of equity and inclusiveness for all participants. 
To further understand the benefits and drawbacks of lecture capture technology, the researchers propose conducting a cost-benefit analysis case study at McMaster University in order to a) pilot the use of lecture capture with closed captioning in a technical discipline like science or engineering and b) pilot it in classroom environments that are not primarily lecture-based. A subsequent investigation focusing on students with reported academic accommodations would help determine whether these results can be generalized to other university environments or other types of organizations. We will also continue to examine issues, both attitudinal and pedagogical, for broader systemic implementation.

\section{Note}

1. Edyburn (2005) distinguishes universal design for learning, which aims to reduce learning barriers for everyone, from assistive technologies, which aim to reduce barriers for those with specific disabilities.

\section{References}

Accessibility for Ontarians with Disabilities Act (AODA). (2005). Retrieved from http://www.e-laws.gov.on.ca/html/statutes/english/elaws_statutes_05a11_e.htm

Association of Universities and Colleges of Canada (AUCC). (2007). University enrolment increases to continue. Retrieved from http://www.aucc.ca/publications/ media/2007/trends_01_05_3.html

Baycrest (2010). Definition of barrier. Retrieved from http://www.baycrest.org/ About_Baycrest/Accessibility_Plan/Appendix/default.asp

Beer, C. (2010). Charting a path forward: Report of the independent review of the Accessibility for Ontarians with Disabilities Act, 2005. Retrieved from http://www.mcss. gov.on.ca/en/mcss/publications/accessibility/charles_beer/tableOfContents.aspx

Brogan, P. (2009). Echo360: Lecture capture solutions for students with disabilities. Retrieved from http://www.automaticsync.com/captionsync/wp-content/uploads/ AccessibleLectures-11.pdf

Burgstahler, S. (2005). Universal design of instruction: Definition, principles, and examples. Retrieved from http://www.washington.edu/doit/Brochures/PDF/ instruction.pdf

Busch-Vishniac, I. (2007). The Contexts of Higher Education is Changing: The State of the Academy. Retrieved from http://www.mcmaster.ca/vpacademic/provost/speeches/ sota082007.pdf

Centre for Student Development (CSD). (2010). It takes a village to raise a child: CSD Annual Report 2010. Retrieved from http://studentaffairs.mcmaster.ca/pdf/2011/ StudentAffairs_AR.pdf.

Council of Ontario Universities (COU). (2010). Ministry of Energy and Infrastructure Consultations on the 1O-year Infrastructure Plan. Retrieved from http://www.cou.on.ca/ issuesresources/student-resources/government-submissions/pdfs/cou-submission_ august-2010_mei-consultations-on-th.aspx 
Edyburn, D.L. (2005). Universal design for learning. Special Education Technology Practice, 7(1), 16-22.

Erzerberger, C., \& Prein, G. (1997). Triangulation: Validity and empirically based hypothesis construction. Quality and Quantity, 31(2), 141-154.

Fernandez, V., Simo, P., \& Sallan, J.M. (2009). Podcasting: A new technological tool to facilitate good practice in higher education. Computers \& Education, 53(2), 385-392.

Flanagan, B., \& Calandra, B. (2005). Podcasting in the classroom. Learning \& Leading with Technology, 33(3), 20-25.

Fuller, M., Healey, M., Bradley, A., \& Hall, T. (2004). Barriers to learning: A systematic study of the experience of disabled students in one university. Studies in Higher Education, 29(3), 303-318.

Hall, T., Meyer, A., \& Strangman, N. (2009). Differentiated instruction and implications for UDL implementation. Retrieved from http://www.cast.org/system/ galleries/download/ncac/DI_UDLNov2.pdf

Hughes, G., \& Robinson, P. (2008). Photonote: The making of a classroom adaptation system. Designing Inclusive Futures, Part IV, 197-206.

Ianiro, S. (2007). Professional development fact sheet no. 2: Universal design for learning. Retrieved from http://www.calproonline.org/documents/ UniversalDesignforLearningFinal.pdf

McKenzie, W. A. (2008). Where are audio recordings of lectures in the new educational technology landscape? Proceedings of the Ascilite Conference, 628-632. Melbourne, Australia. Retrieved from http://www.ascilite.org.au/conferences/melbourneo8/procs/ mckenzie-w.pdf

Ministry of Community and Social Services (MCSS), (2008). About the Accessibility for Ontarians with Disabilities Act, 2005 (AODA). Retrieved from http://www.carlowmayo. ca/documents /Accessibility\%2oBrochure.pdf

Mino, J.J. (2004). Planning for inclusion: Using universal instructional design to create a learner-centered community college classroom. Equity \& Excellence in Education, $37(2), 154-160$.

Nulty, D.D. (2008). The adequacy of response rates to online and paper surveys: what can be done? Assessment \& Evaluation in Higher Education, 33(3), 301-314.

Ontario Human Rights Code (OHRC), (1990). Retrieved from http://www.e-laws.gov. on.ca/html/statutes/english/elaws_statutes_90h19_e.htm

Pliner, S.M., \& Johnson, J.R. (2004). Historical, theoretical, and foundational principles of universal instructional design in higher education. Equity \& Excellence in Education, 7(2), 105-113.

Sax, L.J., Gilmartin, S.K., \& Bryant, A.N. (2003). Assessing response rates and nonresponse bias in web and paper surveys. Research in Higher Education, 44(4), 409432. 
Scott, S.S., McGuire, J.M., \& Foley, T.E. (2003). Universal design for instruction: A framework for anticipating and responding to disability and other diverse learning needs in the college classroom. Equity \& Excellence in Education, 36(1), 40-49.

Vajoczki, S., Watt, S., \& Marquis, N., 2008. Vodcasts: Are they an effective tool to enhance student learning? A case study from McMaster University, Hamilton, Canada. Proceedings of World Conference on Educational Multimedia, Hypermedia and Telecommunications, 4913-4920. Chesapeake, VA: AACE.

Vajoczki, S., Watt, S., Marquis, N., \& Holshausen, K. (2010). Podcasts: Are they an effective tool to enhance student learning? A case study from McMaster University. Journal of Educational Multimedia and Hypermedia. 19(3), 349-362.

Vajoczki, S., Watt, S., Marquis, N., Liao, R., \& Vine, M.M. (2011). Students approach to learning and their use of lecture capture. Journal of Educational Multimedia and Hypermedia, 2O(2), 5-24.

Williams, J. (2006). The Lectopia service and students with disabilities. Proceedings of the 23 $3^{\text {rd }}$ Annual Ascilite Conference: Who's learning? Whose technology?, 881-884. Sydney, Australia. Retrieved from http://www.ascilite.org.au/conferences/sydneyo6/ proceeding/pdf_papers/p67.pdf

Williams, J., \& Fardon, M. (2005). On-demand internet-transmitted lecture recordings: Attempting to enhance and support the lecture experience. Proceedings of the Association for Learning Technology Conference: Exploring the frontiers of e-learning: borders, outposts and migration, 153-161. Manchester, England. Retrieved from http:// www.lectopia.com.au/misc/WilliamsFardon_ALT-C_2005.pdf

\section{Biographies}

Susan Watt

School of Social Work

McMaster University

wattms@mcmaster.ca

Susan Watt, DSW, is Professor Emeriti in the School of Social Work at McMaster University. Dr. Watt is a quantitative researcher specializing in social policy analysis. She was the Associate Dean of Social Sciences when this research was undertaken and had a particular interest in the conditions for the success of students with disabilities in the university environment.

Susan Vajoczki, PhD, was the Director of the McMaster University Centre for Leadership and Learning prior to her untimely death in October 2012. She was Professor of Geography and Earth Sciences at McMaster and had a passion for understanding and enhancing student learning and faculty teaching. Publication of this paper was pursued by Sue's team to honour her groundbreaking contributions to pedagogy.

Geraldine Voros, M.A., is a Teaching Professor in the Department of Health, Aging and Society at McMaster University. Experimenting with different teaching approaches in 
larger classes as the cohort of students shift in terms of special needs and expectations, her goal is to achieve a pedagogy that is inclusive and engaging. Her efforts in education and community service have been recognized with numerous honours and awards.

Michelle Vine, PhD, is a Research Development Officer in the Faculty of Applied Health Sciences at the University of Waterloo. She is a social geographer, with a strong research focus on the environment and health, qualitative research methods, chronic disease health promotion, and the scholarship of teaching and learning. As part of her work with the Centre for Leadership in Learning, she collected and analyzed qualitative interview and focus group data related to teaching and learning in higher education.

Nancy Fenton, PhD, is an Associate Research Professor in the School of Public Health and Health Systems at the University of Waterloo. Dr. Fenton is a qualitative health researcher; her primary research area focuses on the relationships between the environment and health as it relates to risk perceptions and the health literacy of children and youth. She has extensive experience teaching in higher education.

Jacob Tarkowski, B.A., is a multidisciplinary researcher who has experience working in pedagogy, natural resource management, and corporate sustainability. Various internships within the United Nations University network have supplemented his academic work. He is currently pursuing a Masters in Environmental Studies at York University with a focus on corporate sustainability. 


\section{Appendix 1 - Online Survey Questionnaire}

This survey will investigate the perceptions and experiences of faculty members, students, and in particular students' with disabilities use of lecture capture technology in order to understand how it aligns with the new accessibility legislation standards. More specifically, Echo36o, a lecture capturing technology will be the focus of this study and its use of closed captioning.

\section{Section 1: Background Information}

A little background demographic information about yourself.

1. Gender:
a. Female
b. Male
c. Transgendered

2. Age:
a. less than 17
b. $17-19$
c. 20-22
d. $23-25$
e. $26-35$
f. greater than 35

3. What Faculty are you in?
a. Business
b. Engineering
c. Health Sciences
d. Humanities
e. Science
f. Social Sciences
g. Other please specify

4. What level are you in?
a. I
b. II
c. III
d. IV
e. Other Please explain: 
5. Have you ever had access to lecture capturing in a University class before?

a. Yes - Please list course code(s)/name(s):

b. No - Skip to Q. 12

6. Have you ever had access to lecture capturing with closed captioning in a University class before? Closed captioning: display of text on the video screen to provide additional interpretive information.

a. Yes - Please list course code(s)/name(s):

b. No

7. Did you make use of the closed captioning feature of lecture capturing in this class?

Yes “.

No ${ }^{*}$ (Proceed to Q. 9)

8. After using lecture capturing once, what was your frequency of use for the remainder of lecture captures?
a. ALL
b. $75-99 \%$
c. $50-74 \%$
d. $25-49 \%$
e. $10-24 \%$
f. less than $10 \%$

9. In how many university level classes have you had access to lecture capturing?
a. 1
b. $2-3$
c. $3-5$
d. greater than 5

10. Did the availability of captured lectures influence your decision to enroll in this course?
a. Yes
b. No

11. Have you ever used lecture capturing outside of a university class before?
a. Yes
b. No 


\section{Section 2: Utilizing Lecture Capturing}

Now we would like to know a little but about how you utilized lecture capturing.

12. How did you actually make use of the lecture captures available for this course? (Check all that apply)

$\square$ After class for review or clarification

$\square$ Occasionally in place of attending class (i.e., when sick or out of town)

$\square$ Regularly in place of attending class (i.e., no need to attend if it can be listened to at anytime)

$\square$ While studying for tests and exam

$\square$ Occasionally for review

$\square$ Never. Please explain why you chose not to make use of the lecture captures available in this course: - skip to Q. 40

13. Why did you use the lecture captures in this course (check all that apply)?

$\square$ Because they were available

$\square$ Because they helped me understand the course material

$\square$ Because they allowed me to work at my own pace

$\square$ Because they allowed me to miss lectures

Other Please specify:

14. How much of an individual lecture capture did you TYPICALLY use?
a. ALL
b. $75 \%$
c. $50 \%$
d. $25 \%$
e. $10 \%$

15. Each lecture in this course had its own lecture capture. How many of the lecture captures did you access?

f. ALL

g. $75-99 \%$

h. $50-74 \%$

i. $25-49 \%$

j. $10-24 \%$

k. less than $10 \%$ 
16. Where did you access the lecture captures? (Check all that apply).

At home at my desk

At home while completing other tasks

$\square$ At school in a computer lab

At school on a library computer

At school on my wireless laptop

$\square$ At an internet café

$\square$ While commuting

$\square$ Other Please specify:

17. How did you access the lecture captures? (Check all that apply).

$\square$ Desktop computer

$\square$ Laptop computer

$\square$ Game console

$\square$ Television

$\square$ Mp3 player

$\square$ Cell phone

$\square$ Other. Please specify:

\section{Section 3: Academic Accommodations}

Please tell us about your academic accommodations or needs.

18. Do you have an academic accommodation need that has been documented by a Disability Specialist at the Centre for Student Development?

$\square$ Yes

$\square$ No

19. Do you have need for an accommodation that has not been reported?

$\square$ Yes

$\square$ No

Please explain 
20. Did you anticipate that lecture capturing would be helpful for your accommodation need?

$\square$ Yes

$\square$ No

21. Was lecture capturing helpful for your accommodation need?

Yes

$\square$ No

Please explain

22. Do you feel that lecture capturing minimized the need to speak to the professor about your accommodation?

$\square$ Yes

$\square$ No

Please explain

23. Do you have difficulty attending classes due to other commitments, constraints, or confounding factors?

$\square$ Yes

$\square$ No

24. Select any barriers that may apply to your academic situation. (Check all that apply).

\begin{tabular}{|l|l|}
\hline Barrier & Definition \\
\hline Attitudinal & $\begin{array}{l}\text { Refers to persons who do not know how to communicate with } \\
\text { people with disabilities, or persons who display discriminatory } \\
\text { behaviours, etc. }\end{array}$ \\
\hline Architectural & $\begin{array}{l}\text { Refers to building design, areas adjacent to buildings, shape of } \\
\text { rooms, size of doorways, etc. }\end{array}$ \\
\hline $\begin{array}{l}\text { Informational/ } \\
\text { Communications }\end{array}$ & $\begin{array}{l}\text { Difficulties receiving information or communications: either in } \\
\text { person, print material, telephones, signage, verbal, etc. }\end{array}$ \\
\hline Physical & $\begin{array}{l}\text { Refers to objects that are added to the environment -- doors, } \\
\text { windows, elevators, furniture, bathroom hardware, etc. }\end{array}$ \\
\hline $\begin{array}{l}\text { Policy and } \\
\text { Practices }\end{array}$ & $\begin{array}{l}\text { Refers to rules, regulations, and protocols that are restrictive to } \\
\text { persons with disabilities. }\end{array}$ \\
\hline Technology & $\begin{array}{l}\text { Refers to devices such as: computers, telephones, inadequate or } \\
\text { inappropriate assistive technologies, etc. }\end{array}$ \\
\hline
\end{tabular}


$\square$ Attitudinal barrier

$\square$ Architectural barrier

$\square$ Informational/communications barrier

$\square$ Physical barrier

$\square$ Policy and practices

$\square$ Technological barrier

Please explain

25. Select which barriers were alleviated with the use of lecture capturing.

a. Attitudinal barrier

b. Architectural barrier

c. Informational/communications barrier

d. Physical barrier

e. Policy and practices

f. Technological barrier

Please explain

\section{Section 4: Perceptions/Experiences of Lecture Capturing}

It is important to understand how well lecture capturing worked for you; the next set of questions addresses your experience(s) with lecture capturing.

26. How helpful did you find the instructions in explaining how to access the lecture captures?
a. Not at all helpful
b. Somewhat helpful
c. Helpful
d. Very helpful
e. Extremely helpful 
27. How helpful did you find lecture capturing?
a. Not at all helpful
b. Somewhat helpful
c. Helpful
d. Very helpful
e. Extremely helpful

28. How easy was it to use lecture capturing?
a. Not at all easy
b. Somewhat easy
c. Easy
d. Very easy
e. Extremely easy

29. Indicate any aspects of lecture capturing that you thought could be improved. (Check all that apply).
a. Quality of the sound
b. Quality of the visuals
c. Download time
d. Users controls
e. Background noise sound
f. Sound volume
g. Time from lecture to posting
h. Closed captioning
i. Screen reader support
j. Other: please specify 
30. Indicate any aspects that you thought were particularly effective. (Check all that apply).

$\square$ Quality of the sound

$\square$ Quality of the visuals

Download time

$\square$ Users controls

Background noise sound

Sound volume

Time from lecture to posting

$\square$ Closed captioning

$\square$ Screen reader support

$\square$ Other: please specify

31. Lecture capturing provided sufficient choice and flexibility in how it could be used.

32. Lecture capturing allows all students, regardless of learning abilities, an equitable learning experience.

33. Lecture capturing improved my overall understanding of the course material.

34. Lecture capturing helped me retain the knowledge that I learned in this course.

35. The availability of lecture capturing in a future course would encourage me to enroll in that course.

36. My overall satisfaction with this course is greater because of lecture capturing.

37. Lecture capturing allowed me to understand concepts otherwise difficult to follow in class.

38. Lecture capturing did not impede upon my ability to follow the instructor's lecture in class.

\begin{tabular}{|c|c|c|c|c|}
\hline $\begin{array}{c}\text { Strongly } \\
\text { Agree }\end{array}$ & Agree & Neutral & Disagree & $\begin{array}{l}\text { Strongly } \\
\text { Disagree }\end{array}$ \\
\hline & & & & \\
\hline & & & & \\
\hline & & & & \\
\hline & & & & \\
\hline & & & & \\
\hline & & & & \\
\hline & & & & \\
\hline & & & & \\
\hline & & & & \\
\hline & & & & \\
\hline & & & & \\
\hline
\end{tabular}


39. Lecture capturing could benefit from some supplementary online aids, such as (Check all that apply). Please skip if you feel that lecture capturing does not need supplementary online aids.

$\square$ Online office hours

$\square$ Discussion groups

$\square$ Email lists

$\square$ Chat rooms

$\square$ Other Please specify:

$\square$ Lecture capturing does not need supplementary online aids

\section{Can we have your feedback?}

40. Do you have any comments/suggestions on the classroom climate in terms of an inclusive environment?

Note: An inclusive environment is one that aims to reduce barriers and the need for students to report academic or other accommodations. 


\section{Appendix 2 - Student \& Instructor Interview Guides}

\section{Interview Guide (Student)}

1. How long have you been a student at McMaster?

2. Can you please describe any lecture capture experiences you have had previous to the Canadian Children 2003 class?

Follow-ups: If so, which classes?

Did they involve closed captioning?

3. Could you please tell me what the term accessibility means to you? Accommodation?

4. How, if at all, did lecture capturing make this course more inclusive and accessible to you?

Follow-ups: Did you feel that closed captioning further improved inclusiveness and accessibility?

How often did you specifically make use of the closed caption feature after using it the first time?

5. What barriers within the classroom, if any, prevent you from having an accessible and inclusive learning environment?

Follow-ups: $\quad$ Are there any kinds of content you find challenging?

Are there any environmental/institutional factors that raise any problems?

Did lecture capturing alleviate any of these concerns? How about closed captioning?

6. Did you have any particularly striking or memorable experiences relating to accessibility with respect to lecture capturing this term? If so, please describe.

Follow-ups: How about the opposite side of the spectrum (positive/negative)?

7. Could you tell me how you regularly used the lecture captures?

Follow-ups: Do you feel that you developed a reliance on the captures versus attending class? 
8. Do you have an academic accommodation that has or has not been reported to the Centre for Student Development?

Follow-ups: $\quad$ Please describe its nature? (state this is optional)

How did lecture capturing accommodate for it?

Did it make the content more accessible to you? Was it adequate?

Was there anything that you found missing?

Was the need to mention your accommodation to your professor minimized by the availability of lecture capturing?

9. Are there any other ways in which learning materials in this course could be more accessible to you?

10. Generally speaking, did you find lecture capturing helpful? Unhelpful?

11. Please describe anything that you found particularly difficult about accessing or using the lecture captures?

12. What systems and supports, if any, do you think should be put in place to help students in courses that utilize lecture captioning?

13. Is there something important we forgot? Do you have any additional comments you would like to make about lecture capturing within this course or in general?

\section{Interview Guide (Instructor)}

1. How long have you been an instructor at McMaster?

Follow-ups: Have you been in the same role over this time (describe previous roles)?

2. Can you tell me a little about your experience with lecture capture prior to the Canadian Children 2003 class (when, what courses, etc.)?

Follow-ups: Did they involve closed captioning?

3. Can you please describe the Canadian Children 2003 course? (content, class size, etc.)

Follow ups: When did you first teach this course at McMaster? 
4. Are there other things you did in the past that made the course accessible even though you might not have initially conceived of them in this way?

5. Lecture capturing is intended to make this course more inclusive and accessible. In this context, how would you describe your experience?

Follow-ups: Did you feel that closed captioning further improved inclusiveness and accessibility?

6. Thinking back, what barriers do you believe have prevented you from creating an accessible class learning environment?

Follow-ups: $\quad$ Are there any kinds of content you find challenging to make accessible?

Are there any environmental factors that raise problems?

Are there any institutional factors that raise problems?

Did lecture capturing alleviate any of these concerns?

How about closed captioning?

7. Did you have any particularly striking or memorable experiences relating to accessibility with respect to lecture capturing this term? If so, please describe.

Follow-ups: How about the opposite side of the spectrum (if positive given, ask for negative, and vice versa)?

8. From your perspective as an instructor, do you feel that lecture capturing affected the teaching environment, and, if so, could you describe how?

Follow-ups: How about the opposite side of the spectrum (positive/negative)?

9. Can you describe your understanding of Universal Instructional Design (UID)? How, if at all, do you feel that lecture capturing falls within its definition (provided below)? UID Definition: a new paradigm for teaching, learning, and assessment drawing on new brain research and new media technologies to respond to individual learner differences. There is an implicit attempt made in advance to make instruction accessible to everyone regardless of their ability (ex. ramp or curb cut). 
10. What is your understanding of the Accessibility for Ontarians with Disabilities Act? AODA: designed to break down barriers to accessibility in Ontario with a recent review of the legislation recommending the next three standards (communication, employment, and transportation) be combined into one harmonized standard that is expected to be in place by spring 2011.

11. Do you think AODA will force you to make changes in your teaching?

Follow-ups: If so, what sorts of changes do you think you'll need to make? Do you think it will affect your interactions with students?

12. One of the next AODA standards to be implemented will require that information and communications are accessible. How do you think lecture capturing will help in the implementation of this specific standard?

13. For students identified by the Centre for Student Development as having accommodation needs, did you find that lecture capturing addressed any of their needs? Follow-ups: Given your previous experience, how did the number of formal accommodation requests compare to previous years for this course?

14. Are there any ways in which course instructors could be better supported in their use of lecture capturing?

Follow-ups: What are some possible systems or supports?

15. What are your students telling you about lecture capturing?

Follow-ups: Did your students give any specific feedback with respect to closed captioning?

16. Is there something important we forgot? Is there anything else you think we need to know about lecture capturing and the accessibility of teaching and learning at McMaster? 